\title{
A review: Use of plant extracts and their phytochemical constituents to control antibiotic resistance in $S$. aureus
}

\author{
Arshia Nazir ${ }^{1}$, Kausar Malik ${ }^{1 *}$, Husnain Qamar ${ }^{1}$, Muhammad Hamza \\ Basit $^{2}$, Ayesha Liaqat ${ }^{1}$, Muhammad Shahid ${ }^{1}$, Muhammad Islam \\ Khan $^{1}$, Areeba Fatima ${ }^{1}$, Asma Irshad ${ }^{1}$ and Haleema Sadia ${ }^{3}$ \\ 1. National Centre of Excellence in Molecular Biology, University of the Punjab, Lahore-Pakistan \\ 2. Virtual University of Pakistan \\ 3. Balochistan University of Information Technology, Engineering and Management Sciences-Pakistan \\ *Corresponding author's email: kausarbasit786@yahoo.com \\ Citation \\ Arshia Nazir, Kausar Malik, Husnain Qamar, Muhammad Hamza Basit, Ayesha Liaqat, Muhammad Shahid, \\ Muhammad Islam Khan, Areeba Fatima, Asma Irshad and Haleema Sadia. A Review: Use of plant extracts and \\ their phytochemical constituents to control antibiotic resistance in S. aureus. Pure and Applied Biology. Vol. 9, \\ Issue 1, pp720-727. http://dx.doi.org/10.19045/bspab.2020.90078
}

\begin{tabular}{llll}
\hline \hline Received: 12/09/2019 & Revised: 01/12/2019 & Accepted: 10/12/2019 & Online First: 23/12/2019 \\
\hline \hline
\end{tabular}

\section{Abstract}

Although the invention of antibiotics has reduced the morbidity and mortality due to infectious diseases but the inappropriate use of antibiotics both for humans and animals has led to the emergence of multidrug resistant strains of bacteria and fungi. Among the antibiotic resistant pathogens, S. aureus is the pathogen of greatest concern due to its intrinsic virulence, its ability to cause a large number of infections and to survive under various environmental conditions. Modification of antibiotic ( $\beta$-lactamases), use of alternative target site (PBP2a), efflux of antibiotics (NorA) and biofilm formation are some of the mechanisms utilized by $S$. aureus to develop resistance against antibiotics. This has lead to the increased interest in traditional medicine that has long been used to cure various infectious diseases at different regions of the world. Plant extracts serve as an important source to combat microbial resistance because they consist of complex mixture of phytochemical constituents against which the development of resistance is very slow. In additions, phytochemical constituents present in the plant extracts also act as immunomodulatory and anti-inflammatory agents. The current study aims at stimulating the search of plant extracts and their phytochemical constituents to control microbial resistance. In future, plant extracts as well as their purified constituents could be used as potent therapeutic agents for the treatment of infections caused by $S$. aureus without obvious side effects.

Keywords: $\beta$-lactamases; Biofilm formation; Efflux pump; Multidrug resistance; Phytochemical constituents; Plant extracts

\section{Introduction}

Discovery of penicillin in 1929 not only revolutionized the field of antibacterial therapy but also led to the discovery of large number of effective antibiotics from bacteria and fungi. However, in 1940s, penicillin-resistant strains of microbes began to appear due to its widespread use $[1,2]$. Similarly, bacteria have developed resistance to other commonly used antibiotics [3]. Necessity is the mother of invention; therefore, a man is in continuous search for the discovery of new remedies to control the infectious diseases and 
emerging resistance of microbes. Plants especially herbs have been used to cure diseases since ancient times. About $80 \%$ of the world population living in developing countries relies on herbs as well as other medicinal plants for therapeutic purposes and their uses are increasing day by day due to the side effects of allopathic medicine [4]. For the promotion and development of herbal medicine, World Health Organization has made a strategic plan which includes four areas: a) Recognition of herbal medicines as valuable resources and promotion of their use. b) Development of comprehensive program for identification, cultivation and recognition of herbal medicines as valuable products. c) Introduction of measures for the assessment of medicinal plants to ensure the quality control of plant based products in order to include the herbal medicines in the national standard or pharmacopoeia. d) Development of programs by international cooperation and coordination for the conversation of plants that serve as valuable source of traditional or modern drugs in order to prevent their extinction [5].

S. aureus as an alarm to human health

In early 1970s, optimistic view of physicians that virtually all bacterial infections can be controlled by using a wide array of antimicrobial agents, was shaken due to the emergence of antibiotic resistant strains of bacteria (Staphylococcus aureus, Streptococcus pneumoniae, Pseudomonas aeruginosa, and Mycobacterium tuberculosis). Several factors contributed to the evolution of these antibiotic-resistant pathogens and one of these factors is the widespread use of antibiotics to control both human and animal infections $[6,7]$. Among the antibiotic resistant strains, $S$. aureus is the pathogen of greatest concern due to its intrinsic virulence, its ability to cause a large number of infections and to survive under different environmental conditions [8]. Besides the availability of effective antimicrobial agents, the mortality rate for $S$. aureus bacteremia remains approximately 20-40\% [9]. Now, S. aureus is the leading cause of a variety of community and hospital acquired infections ranging from mild skin infections to severe infections including osteomyelitis, pneumonia, endocarditis and sepsis [10].

Molecular mechanisms of antibiotic resistance

\section{Resistance to penicillins}

Development of antibiotic resistance has changed the strategy to treat $S$. aureus associated infections In the late 1960s, more than $80 \%$ of both community and hospital acquired $S$. aureus strains were found to be resistant to penicillins. Rapid emergence of penicillin resistance was due to the horizontal transfer of blaZ gene that encodes $\beta$-lactamase enzyme. This enzyme hydrolyzes the $\beta$-lactam ring of penicillins and thereby rendering them ineffective [11].

\section{Resistance to methicillin}

To overcome the problems of penicillins, semisynthetic penicillinase resistant penicillin called methicillin was introduced in 1961 but its introduction was followed by a large number of cases of methicillin resistant $S$. aureus [12]. Resistance to penicillin is due to the presence of mecA gene that encodes penicillin binding protein $2 \mathrm{a}$ (PBP2a or PBP2') and is located on chromosomal island designated as staphylococcal cassette chromosome mec (SCCmec). PBP2a is a membrane bound enzyme that catalyzes the cross-linking of peptidoglycan chains $[13,14]$. PBP2a has low affinity with $\beta$-lactam antibiotics and thereby allowing the $S$. aureus to survive in the presence of high concentrations of $\beta$ lactam agents. mecA gene confers resistance not only to $\beta$-lactam agents but also to Cephalosporins [15]. Continued use of vancomycin to control MRSA infections in hospitals led to the emergence of vancomycin resistant MRSA strains. A case of an MRSA with reduced susceptibility to vancomycin was first reported in 1997 in Japan. Resistance to vancomycin is due to the mutations in the genes that are involved in the biosynthesis of cell envelope [16].

\section{Resistance to fluoroquinolones}


Another mechanism of resistance to antibiotics utilized by $S$. aureus is to reduce the intracellular concentration of antibiotics. Reduction in intracellular concentration of antibiotics is achieved either by decreasing the membrane permeability or by efflux of antibiotic out of the cell $[17,18]$. The purpose of these efflux pumps is the elimination of intracellular metabolites that are toxic to cell. In addition, bacterial efflux pumps also play their role in the secretion of virulence determinants (hemolysins, proteases, coagulases and clumping factors) and maintenance of cell under stress conditions [19]. Some efflux pumps are specific, extruding only one antibiotic or a class of antibiotics whereas others can extrude several classes of antibiotics and are designated as multidrug resistance (MDR) efflux pumps. Until now, more than ten MDR efflux pumps have been identified in $S$. aureus. NorA is one of the most studied MDR efflux pump of $S$. aureus that is encodes by the chromosomal gene norA. NorA efflux pump was first reported in fluoroquinolone-resistant (Figure 1) bacterial strain isolated from a patient at Japanese Hospital in 1986 [20]. NorA comprises 388 amino acids and it consists of 12 membrane spanning segments. It shares $44 \%$ identity with Bacillus subtilis MDR efflux pump Bmr while it shares 24\% identity with Escherichia coli tetracycline resistant efflux pump TetA. NorA efflux pump plays a significant role in the efflux of fluoroquinolones and dyes such as ethidium bromide and rhodamine [21].

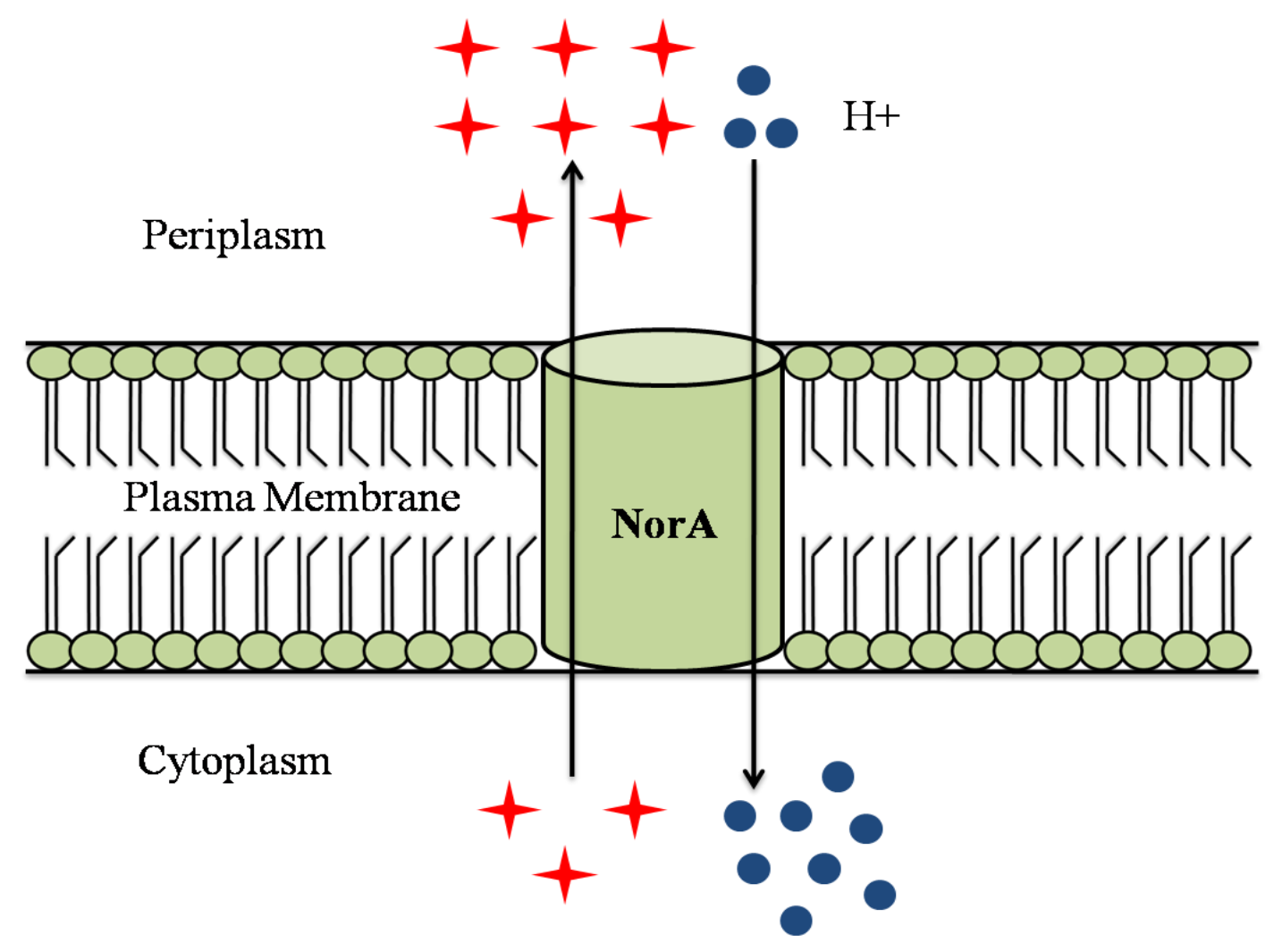

Fluoroquinolones

Figure 1. Efflux of fluoroquinolones by NorA. NorA utilizes the energy derived from proton motive force for pumping fluoroquinolones out of the cell, thereby providing resistance to $S$. aureus against fluoroquinolone antibiotics

\section{Biofilm formation}

In addition to $\beta$-lactamases, PBP2a and efflux pumps, another weapon utilized by $S$. aureus to develop resistance to antibiotics 
is the formation of biofilms. Biofilm formation is used as a defense mechanism by $S$. aureus as it provides protection against host defense system and antibiotic therapy. Moreover, biofilm associated infections are more chronic and mostly occur in hospitals [22]. Biofilm formation in $S$. aureus involves three steps: initial attachment of bacteria to biotic or abiotic surface, proliferation which is preceded by the production of ECM (extracellular matrix) that consists of extracellular polysaccharides, teichoic acid and DNA released by lysed cells, and final step of biofilm production is the detachment. Detachment of biofilm is under the control of quorum sensing system Agr but the quorum sensing control of biofilm detachment in $S$. aureus is not yet defined. However, the enzymes that can degrade the biofilm polymers have been identified in $S$. aureus [23-25]. Due to biofilm formation, $S$. aureus including MRSA are found to be resistant to Clindamycin which was once effectively used to control $S$. aureus associated infections. Now, Linezolid and Vancomycin can be used to control the serious infections of $S$. aureus [26]. At present, there is a need for the search and development of new antimicrobial agents other than antibiotics to overcome the microbial resistance.

Use of botanicals to combat bacterial antibiotic resistance

In order to combat emerging microbial drug resistance, botanicals including herbs, shrubs and traditional medicine could be used as alternative to antibiotics. A variety of compounds is produced by the plants that are not required for their primary metabolism but significantly increases the adaptive capability of the plant to survive under unfavorable biotic and abiotic environments. The secondary metabolites of the plants (alkaloids, phenols, flavonoids, quinones, tannins, terpenes and lectins) are well known to provide defense against herbivores and microbes [27, 28]. Methanolic leaf extract of Yucca aloifolia was found to be rich source of alkaloids, flavonoids, saponins, tannins and steroids [29]. Besides this, hydro-alcoholic extract of the flowers of Calliandra haematocephala also serves as a rich source of phytochemical constituents (alkaloids, flavonoids, saponins, tannins, glycosides, carbohydrates and steroids) and exhibited strong antibacterial activity against $S$. aureus at the concentration of $100 \mu \mathrm{g} / \mathrm{ml}$ by agar well diffusion assay [30].

\section{Alkaloids}

Among the secondary metabolites of plants, alkaloids are the group of heterocyclic nitrogen containing compounds that act as pain relievers and can also be used as narcotics. Alkaloids such as harmane and berberine also intercalate with DNA and thereby resulting in impairment of cell division [31].

\section{Phenols}

Phenols are aromatic secondary metabolites of plants that are further divided into flavonoids, quinones, tannins and coumarins. Flavonoids are the phenolic compounds of plants that are present in edible parts of plants (vegetables, fruits and nuts). Antimicrobial activity of flavonoids resides in their ability to increase the permeability and disruption of plasma membrane by interacting with membrane proteins present on bacterial cell wall. In addition, flavonoids also have antiinflammatory and antitumor activities [31]. Quinones are the aromatic compounds with two ketone substitutions. Antimicrobial activity of quinones is due to their binding to cell surface adhesin proteins, cell wall polypeptides and enzymes bound to membranes [32]. Tannins are the phenolic compounds that are found in all parts of a plant and are known to have antibacterial and antifungal activities. Their antimicrobial activity is due to their ability to inactivate transport proteins as well as cell surface adhesins [33]. Coumarins such as chalocones and scopoletin which have been recently isolated from Fatoua pilosa, consist of benzene ring fused to alpha pyrone ring and have antitubercular activity [34]. 


\section{Terpenes}

Terpenes form the largest group of natural compounds and their identification is done on the basis of isoprene units they possess. Terpenoids which are the derivatives of terpenes exhibit antibacterial effects but their mechanism of antibacterial activity is not clearly defined. It is estimated that terpenoids work by disrupting the bacterial membranes [35].

\section{Lectins}

Lectins are larger than polypeptides and contain mannose containing molecules. Their antimicrobial activity is due to their ability to compete with bacterial cell surface adhesion molecules for binding to host polysaccharide receptors [36, 37].

\section{Other antimicrobial phytochemicals}

Besides alkaloids, phenolic compounds and lectins, many other phytochemicals have also been reported to exert antibacterial activities. There are some reports on the antibacterial activities of polyamines (spermidine), glucosides, thiosulfinates and isothiocyanates. In Brazil, acetylene compounds and flavonoids derived from plant are traditionally used for the treatment of malaria and liver disorders. Cranberry and blueberry juices have been used for therapeutic purposes for the treatment of urinary tract infections. In 1990s, researchers found that monosaccharide fructose present in cranberry and blueberry juices competitively inhibit the adsorption of pathogenic E. coli to epithelial cells of urinary tract [38].

\section{Mechanism of action of botanicals}

Bacteria used efflux pumps as a mechanism to develop resistance to antibiotics so interfering with the functions of these efflux pumps would be an interesting therapy to control infectious diseases. Various plant derived compounds such as reserpine, berberine, methoxylated flavones and isoflavones have putative inhibitory effects on efflux pumps [39]. The alkaloid reserpine from Rauvolfia vomitoria, terpenecarnosic acid from Rosmarinus officinalis and the diterpenetotarol from Chamaecyparis nootkatensis inhibit the function of NorA of $S$. aureus. Another inhibitor of NorA is 5-methoxyhydnocarpin. It was reported that 5-methoxyhydnocarpin significantly increased the antimicrobial activity of berberine (an alkaloid) in the same plant [40]. Besides inhibiting the function of efflux pumps, various plant extracts affect the virulence factors of bacteria especially $P$. aeruginosa with altering the quorum sensing (QS) gene expression [41]. Extracts of Berberis aristata and Camellia sinesis showed antibacterial effects by targeting the hemolysins and hemagglutination on bacterial cell surface [42]. Sub-inhibitory concentrations of various plant extracts affect the virulence of both gram positive and gram negative bacteria $[43,44]$. In addition, various plant extracts have immunomodulatory effects. Since the plant extracts consist of complex mixture of phytochemical constituents, emergence of microbial resistance to the complex mixture of compounds may be much slower than those of antibiotics [45].

\section{Prevention of skin-associated infections by plant based antiseptic soaps}

In order to prevent, control and reduce microbial infections, hand washing is crucial. Health care workers are potent source of transmission of MDR pathogens from one person to another. Proper hand washing and drying terminate the chain of transmission of pathogens from hands to other body parts. Hence, hand sanitizers and antiseptic soaps are being utilized for hand washing purposes. Although, chemical antiseptic soaps have played a vital role in reducing the transmission of infectious diseases but they have some adverse effects including skin irritation and microbial resistance [46]. In order to overcome the problems associated with chemical antiseptic soaps, there is a need for the development of plant based antiseptic 
soaps that will be less toxic and inexpensive [47]. Researchers are now in continuous search for the development and evaluation of plant based soaps that may be used as alternatives to harmful synthetic soap products. It is not surprising to find that synthetic foaming agent sodium lauryl sulfate (SLS) in soaps is replaced by saponins [48], synthetic antibacterial agents such as Triclosan are replaced with natural antimicrobial agents [49] and synthetic antioxidant agents such as BHT (butylated hydroxytoluene) are replaced with phenolic compounds [50].

\section{Conclusion}

Discovery of antibiotics is marked as a significant scientific advancement in the field of medicine as they helped in controlling $S$. aureus associated infections. But an inappropriate use of antibiotics has led the evolution of $S$. aureus strains that are not only resistant to conventional antibiotics like penicillins but also resistant to other previously used antibiotics like fluoroquinolones. To overcome the emerging resistance of microbes, plant extracts and their phytochemical constituents are of great importance. Plant extracts are complex mixture of phytochemical constituents against which the development of microbial resistance is very slow. In addition, purified phytochemical constituents of plants have strong antimicrobial properties and are of great interest in scientific community. Not surprisingly, traditional medicinal plants and their purified phytochemical constituents are now increasingly employed to control microbial infections. Another application of plant extracts and their phytochemical constituents in their incorporation in antiseptic hand washing soaps as appropriate hand washing can terminate the chain of transmission of $S$. aureus from hands to other body sites of the same or different person.

\section{Authors' contributions}

Conceived and designed the experiments: A Nazir, K Malik, H Qamar, MH Basit, A
Liaqat, M Shahid, MI Khan, A Fatima, A Irshad \& $H$ Sadia, Performed the experiments: A Nazir, K Malik, H Qamar, MH Basit, A Liaqat, M Shahid, MI Khan, A Fatima, A Irshad \& H Sadia, Analyzed the data: A Nazir, K Malik, H Qamar, MH Basit, A Liaqat, M Shahid, MI Khan, A Fatima, A Irshad \& H Sadia, Contributed materials/ analysis/ tools: A Nazir, $\mathrm{K}$ Malik, H Qamar, MH Basit, A Liaqat, M Shahid, MI Khan, A Fatima, A Irshad \& H Sadia, Wrote the paper: A Nazir, K Malik, H Qamar, MH Basit, A Liaqat, M Shahid, MI Khan, A Fatima, A Irshad \& H Sadia.

\section{References}

1. Abraham EP \& Chain E (1940). An enzyme from bacteria able to destroy penicillin. Nat 146: 837.

2. Rammelkamp CH \& Maxon T (1942). Resistance of Staphylococcus aureus to the action of penicillin. Experimen Biol and Medic 51: 386-389.

3. Davies J \& Davies D (2010). Origins and evolution of antibiotic resistance. Micro Biol and Molecu Biol Reviews 74: 417433.

4. Verma S \& Singh SP (2008). Current and future status of herbal medicine. Veterin World

5. 2: 347-350.

6. World Health Organization, Regional Office for the Western Pacific (1998). Guidelines for the appropriate use of herbal medicines. Manila: WHO Regional Office for the Western Pacific, 1998 (Report No. 23).

7. Cohen ML (1992). Epidemiology of drug resistance: implications for a postantimicrobial era. Sci 257: 1050-1055.

8. Swartz MN (1997). Use of antimicrobial agents and drug resistance. The New Engl J of Medic 337: 491-492.

9. Lowy FD (1998). Staphylococcus aureus infections. The New Engl J of Medic 339: 520-532.

10. Mylotte JM, McDermott C \& Spooner JA (1987). Prospective study of 114 consecutive episodes of Staphylococcus aureus bacteremia. Revi of Infect Diseases 9: 891-907.

11. Diekema DJ, Pfaller MA, Schmitz FJ, Smayevsky J, Bell J, Jones RN \& Beach M(2001). Survey of Infections Due to 
Staphylococcus Species: Frequency of Occurrence and Antimicrobial Susceptibility of Isolates Collected in the United States, Canada, Latin America, Europe, and the Western Pacific Region for the SENTRY Antimicrobial Surveillance Program, 1997 - 1999. Clinic Infect Diseases 32: S114-S132.

12. Chambers HF (2001). The changing epidemiology of Staphylococcus aureus? Emerg Infect Diseases 7: 178-182.

13. Jevons MP (1961). "Celbenin"-resistant staphylococci. Brit Med J 1: 124-125.

14. Ghuysen JM (1994). Molecular structures of penicillin-binding proteins and betalactamases. Trends in Microbiol 2: 372380.

15. Song MD, Wachi M, Doi M, Ishino F \& Matsuhashi M (1987). Evolution of an inducible penicillin-target protein in methicillin-resistant Staphylococcus aureus by gene fusion. FEBS Lett 221: 167-171.

16. Lim D \& Strynadka NC (2002). Structural basis for the beta lactam resistance of PBP2a from methicillin-resistant Staphylococcus aureus. Nature Struct Biol 9: 870-876.

17. Hiramatsu K, Hanaki H, Ino T, Yabuta K, Oguri T \& Tenover FC (1997). Methicillin-resistant Staphylococcus aureus clinical strain with reduced vancomycin susceptibility. J of Antimicrob Chemother 40: 135-136.

18. Alekshun MN \& Levy SB (2007). Molecular mechanisms of antibacterial multidrug resistance. Cell 128: 1037-1050.

19. Piddock LJ (2006). Clinically relevant chromosomally encoded multidrug resistance efflux pumps in bacteria. Clin Microbiol Revi 19: 382-402.

20. Poole K (2008). Bacterial multidrug efflux pumps serve other functions. Microbe 3: 179-185.

21. Ubukata K, Itoh-Yamashita N \& Konno M (1989). Cloning and expression of the nor A gene for fluoroquinolone resistance in Staphylococcus aureus. Antimicrob Agents and Chemother 33: 1535-1539.

22. Yoshida H, Bogaki M, Nakamura S, Ubukata K \& Konno M (1990). Nucleotide sequence and characterization of the Staphylococcus aureus norA gene, which confers resistance to quinolones. $J$ of Bacteriol 172: 6942-6949.
23. Croes S, Deurenberg RH, Boumans ML, Beisser PS, Neef C \& Stobberingh EE (2009). Staphylococcus aureus biofilm formation at the physiologic glucose concentration depends on the $S$. aureus lineage. BioMed Cent Microbiol 9: 229.

24. Boles BR \& Horswill AR (2008). Agrmediated dispersal of Staphylococcus aureus biofilms. PLoS patho 4: e1000052.

25. Mann EE, Rice KC, Boles BR, Endres JL, Ranjit D, Chandramohan L, Tsang LH, Smeltzer MS, Horswill AR \& Bayles KW (2009). Modulation of eDNA release and degradation affects Staphylococcus aureus biofilm maturation. PloS one 4: e5822.

26. Vuong C, Saenz HL, Götz F \& Otto M (2000). Impact of the agr Quorum-Sensing System on Adherence to Polystyrene in Staphylococcus aureus. The J of Infect Dise 182: 1688-1693.

27. Belbase A, Pant ND, Nepal K, Neupane B, Baidhya R, Baidya R \& Lekhak B (2017). Antibiotic resistance and biofilm production among the strains of Staphylococcus aureus isolated from pus/wound swab samples in a tertiary care hospital in Nepal. Annals of Clinic Microbiol and Antimicrob 16: 15.

28. Stefanović O \& Comic L (2012). Synergistic antibacterial interaction between Melissa officinalis extracts and antibiotics. J of Appl Pharmaceut Sci 2: 15.

29. Wink M, Ashour ML \& El-Readi MZ (2012). Secondary Metabolites from Plants Inhibiting $\mathrm{ABC}$ Transporters and Reversing Resistance of Cancer Cells and Microbes to Cytotoxic and Antimicrobial Agents. Front in Microbiol 3: 1-15.

30. Sobia A, Zubair M, Rasool N \& Anjum F (2013). Antioxidant, antibacterial, antifungal activities and phytochemical analysis of dagger (Yucca aloifolia) leaves extracts. $J$ of Medic Plants 7: 243-249.

31. Tiwari J \& Shukla AK (2016). Investigations on Calliandra haematocephala flowers extract for invitro anthelmintic. Adva Pharmaceut $J 1$ : 17-20.

32. Savoia D (2012). Plant-derived antimicrobial compounds: alternatives to antibiotics. Future Microbiol 7: 979-990. 
33. Ciocan D \& Bara I (2007). Plant products as antimicrobial agents. Analele Ştiinţifice ale Universităţii "Alexandru Ioan Cuza", Secţiunea Genetică şi Biologie Moleculară 8: 151156.

34. Munyendo WLL, Orwa JA, Rukunga GM \& Bii CC (2011). Bacteriostatic and bactericidal activities of Aspilia mossambicensis, Ocimum gratissimum and Toddalia asiatica extracts on selected pathogenic bacteria. Res $J$ of Medici Plants 5: 717-727.

35. García A, Bocanegra-García V, PalmaNicolás JP \& Rivera G (2012). Recent advances in antitubercular natural products. Europ J of Medici Chem 49: 123.

36. Termentzi A, Fokialakis $\mathrm{N} \&$ Skaltsounis AL (2011). Natural resins and bioactive natural products thereof as potential antimicrobial agents. Current Pharmaceut Design 17: 12671290.

37. Balzarini J, Schols D, Neyts J, Van Damme E, Peumans W \& De-Clercq E (1991). Alpha-(1-3)- and alpha-(1-6)-Dmannose-specific plant lectins are markedly inhibitory to human immunodeficiency virus and cytomegalovirus infections in vitro. Antimicrob Agents and Chemother 35: 410-416.

38. Zhang Y \& Lewis K (1997). Fabatins: new antimicrobial plant peptides. FEMS Microbiol Lett 149: 59-64.

39. Zafriri D, Ofek I, Adar R, Pocino M \& Sharon N (1989). Inhibitory activity of cranberry juice on adherence of type 1 and type $\mathrm{P}$ fimbriated Escherichia coli to eucaryotic cells. Antimicrob Agents and Chemother 33: 92-98.

40. Stavri M, Piddock LJV \& Gibbons S (2007). Bacterial efflux pump inhibitors from natural sources. $J$ of Antimicrob Chemother 59: 1247-1260.

41. Holler JG, Christensen SB, Slotved H, Rasmussen HB, GuzMan A, Oslen CE, Petersen B \& Mølgaard P (2012). Novel inhibitory activity of the Staphylococcus aureus NorA efflux pump by a kaempferol rhamnoside isolated from Persea lingue Nees. $J$ of Antimicrob Chemother 67: 1138-1144.
42. Adonizio A, Leal SM, Ausubel FM \& Mathee K (2008). Attenuation of Pseudomonas aeruginosa virulence by medicinal plants in Caenorhabditis elegans model system. J of Med Microbiol 57: 809813.

43. Thakur P, Chawla R, Narula A, Goel R, Arora R \& Sharma RK (2016). Anti-hemolytic, hemagglutination inhibition and bacterial membrane disruptive properties of selected herbal extracts attenuate virulence of Carbapenem Resistant Escherichia coli. Microb Pathogen 95: 133-141.

44. Mooyottu S, Kollanoor-Johny A, Flock G, Bouillaut L, Upadhyay A, Sonenshein AL \& Venkitanarayanan K (2014). Carvacrol and trans-cinnamaldehyde reduce Clostridium difficile toxin production and cytotoxicity in vitro. Int $J$ of molecu scien 15: 4415-4430.

45. Upadhyaya I, Upadhyay A, KollanoorJohny A, Darre MJ \& Venkitanarayanan K (2013). Effect of plant derived antimicrobials on Salmonella enteritidis adhesion to and invasion of primary chicken oviduct epithelial cells in vitro and virulence gene expression. Inter $J$ of molecu scien 14: 10608-10625.

46. Cos P, Vlietinck AJ, Berghe DV \& Maes L (2006). Anti-infective potential of natural products: how to develop a stronger in vitro 'proof-ofconcept'. J of Ethnopharmacol 106: 290-302.

47. Joshi MG, Kamat DV \& Kamat SD (2008). Evaluation of herbal handwash formulation. Nat Prod Radian 7: 413-415.

48. Marjorie MC (1999). Plant products as antimicrobial agents. Clin Microbiol Revi 12: 564-582.

49. Chen YF, Yang CH, Chang MS, Ciou YP $\&$ Huang YC (2010). Foam properties and detergent abilities of the saponins from Camellia oleifera. Inter $J$ of Molecu Sci 11: 4417-4425.

50. Glaser A (2004). The Ubiquitous Triclosan-A common antibacterial agent exposed. Beyond Pesticides/ National Coalition against the Misuse of Pesticides 24: 12-17. 